\title{
The distribution of eosinophils and lymphocytes in the large and small airways of asthmatics
}

\author{
N. Carroll*, C. Cooke**, A. James*
}

The distribution of eosinophils and lymphocytes in the large and small airways of asthmatics. N. Carroll, C. Cooke, A. James. @eERS Journals Ltd 1997.

ABSTRACT: Airway inflammation in asthma consists of variably increased numbers of mononuclear and polymorphonuclear cells, and there is a growing body of evidence to suggest a primary role for lymphocytes and eosinophils in the pathogenesis of asthma. The aim of this study was to examine the distribution of lymphocytes and eosinophils in the bronchial tree of cases of mild and severe asthma.

In cases of fatal asthma $(n=10)$, nonfatal asthma (sudden nonrespiratory death with a history of asthma $n=10$ ), and control cases (sudden death with no history of respiratory illness, $n=10$ ), lymphocytes and eosinophils were counted in transverse sections of large and small airways stained with haematoxylin and eosin.

Cases of fatal asthma had longstanding severe asthma and nonfatal cases generally had mild asthma. Lymphocytes were increased in all airway size groups both in fatal and nonfatal cases of asthma compared to control cases $(p<0.001)$. Eosinophils were increased $(\mathbf{p}<\mathbf{0 . 0 0 1})$ in all airway size groups in the cases of fatal asthma compared to the nonfatal asthma and control groups, which were similar. These differences between case groups were of similar magnitude, when only a random single airway section from each case in each size group was examined. The numbers of lymphocytes correlated with the number of eosinophils in the fatal asthma group $(r=0.60 ; p<0.0001)$, and to a lesser extent in the nonfatal $(r=0.34$; $\mathrm{p}=0.001)$ and control groups $(\mathrm{r}=0.32 ; \mathrm{p}=0.001)$.

These findings suggest that increased numbers of lymphocytes are uniformly distributed in the large and small airways in cases of asthma, independently of asthma severity, and that eosinophil recruitment may be related to asthma severity. Hence, biopsy specimens of the proximal airways are likely to be representative of the cellular infiltrate in large and small airways in mild and severe asthma. Eur Respir J 1997; 10: 292-300.
*Dept of Pulmonary Physiology, Sir Charles Gairdner Hospital, Nedlands, Western Australia. **Dept of Forensic Pathology, State Health Laboratories, QEII Medical Center, Perth, Western Australia.

Correspondence: A. James

Dept of Pulmonary Physiology

Sir Charles Gairdner Hospital

Verdun Street

Nedlands 6009

Western Australia

\section{Keywords: Asthma}

eosinophils

inflammation

lymphocytes

morphometry

Received: June 291996

Accepted after revision November 241996
Increased numbers of polymorphonuclear cells (mainly eosinophils) and mononuclear cells (mainly lymphocytes) have been identified at autopsy in the airways of patients dying of asthma [1-3] and in patients with less severe asthma, by use of bronchoalveolar lavage (BAL) [4-7] and biopsy of proximal airways [7-15]. Immunohistochemical techniques have identified the CD4+ subset of T-lymphocytes in the airways of patients with asthma, and have demonstrated that these lymphocytes and eosinophils express markers of functional activation to a greater extent than those from nonasthmatic subjects $[11,12,15,16]$.

Little is known about the distribution of inflammation in the airways of patients with asthma. Postmortem studies tend to be selective of grossly affected central airways, fibreoptic biopsy samples only a few proximal sites, and BAL is nonspecific and will include cells both from proximal and distal airspaces.

Bronchial biopsy is being used with increasing frequency in clinical studies of asthma. If biopsies are to be used to relate pathological markers of asthma to clinical severity or therapeutic efficacy, then the extent to which proximal bronchial biopsies represent overall airway inflammation needs to be examined. More specifically, it is not clear whether differences in biopsy site influence the variability of airway pathology observed between cases or groups. Several studies have examined the variation in inflammatory cell numbers between proximal sites in the bronchial tree, and have found no differences in cell numbers between sites [12, 14, 17], but we are not aware of any studies comparing inflammatory cell numbers in proximal and distal airways.

In this study, a stratified random sampling method was used to systematically examine the distribution of eosinophils and lymphocytes both in central and peripheral airways of cases of mild and severe asthma and to compare them with cases without asthma.

\section{Methods}

\section{Cases}

The left or right lung of individuals coming to Coroner's autopsy within the metropolitan area of Perth, 
Western Australia, was obtained if the cause of death was asthma or if death occurred suddenly without chest trauma or illness (other than asthma). The lungs were inflated via the main bronchus with $10 \%$ buffered formalin to an initial pressure of $25 \mathrm{cmH}_{2} \mathrm{O}$. The main bronchus was then tied and the whole lung immersed in formalin for at least $48 \mathrm{~h}$. In each case selected, the Coroner's office sent a letter to the relatives of the deceased informing them of the study and inviting them to contact the chief investigator by telephone, or to return an enclosed questionnaire concerning the deceased.

The questionnaire contained questions concerning: any past illness, asthma, chest illness, wheeze or hay fever; frequency of wheeze/asthma; medications and their frequency of use; time away from school or work due to asthma; admissions to hospital due to asthma; and smoking habits. Using the name and age of each subject, any available hospital records were obtained. In Perth, the four main teaching hospitals have common hospital file numbers and the records of any visits to these hospitals (including the emergency department) were examined to obtain information regarding previous medical history, especially asthma (or lack of it), medications, smoking history and lung function testing. Lung function was recorded as the postbronchodilator forced expired volume in one second (FEV1) measured most recently, but remote from the events leading to death. From hospital or Coroner's files, the deceased's usual medical practitioner was identified and contacted by the chief investigators, and invited to complete a questionnaire regarding the deceased's medical history. This questionnaire was similar to that sent to relatives but also enquired about measurements of lung function.

From the information obtained, cases were categorized as: 1) control, no history of asthma, wheeze, use of asthma medications or other lung disease $(n=10) ; 2)$ nonfatal asthma, died suddenly of nonrespiratory causes but subsequently found to have a definite history of asthma from relatives, usual medical practitioner or hospital files $(n=10)$ (for this study, cases were classified as having had asthma if there was a positive questionnaire response to a history of asthma ever, and where there was no history of other pulmonary or cardiac disease); 3) fatal asthma, where asthma was given as the cause of death at autopsy, where the report of events prior to death was consistent with asthma, where cardiovascular and cerebral causes of death were excluded as a cause of death, and where a history of asthma (as above) was obtained from relatives, medical practitioner or hospital files $(n=10)$. Cases were excluded from the study if details of their medical history could not be obtained.

\section{Tissue sampling and processing}

Following fixation, blocks of all large and small cartilaginous airways, which could be cut in transverse section and which were free from branching, were obtained from each case using a stratified random sampling technique. Membranous airways were sampled by cutting six $3 \times 2 \times 1 \mathrm{~cm}$ parenchymal sections at random from the midsaggital slice of the lung. All sections were processed through a series of graded alcohols and embedded in paraffin wax, sectioned $(5 \mu \mathrm{m})$ and stained with haematoxylin and eosin. A smaller sample of serial sections obtained from the same tissue blocks were stained using the immunoperoxidase technique, with monoclonal antibodies directed against the leucocyte common antigen (Dako-CD45RB), "primed" T-cells (Dako-CD450, UCHL1), and B-cells (Dako-L26).

\section{Measurements}

Using a light microscope, camera lucida, and digitizing tablet connected to a mini computer, measurements were made on airways that were cut in transverse section, defined by even thickness of mucosa and submucosa. The internal area $(\mathrm{Ai})$ and perimeter $(\mathrm{Pi})$ defined by the luminal border of the airway epithelium; the area $(\mathrm{Abm})$ and perimeter $(\mathrm{Pbm})$ defined by the basement membrane; the area $(\mathrm{Am})$ and perimeter $(\mathrm{Pm})$ defined by the outer border of the airway smooth muscle; and the total area $(\mathrm{Ao})$ and perimeter $\left(\mathrm{Po}_{\mathrm{o}}\right)$ defined by the adventitial surface of the airway were measured. Where the airway was too large to be viewed entirely using a $\times 4$ objective lens on the microscope, the slide was enlarged using a Nikon Profile Projector (Model 6C; Nippon Kogaku, Japan) and the image was traced onto transparent plastic sheets for measurement on the digitizing tablet.

\section{Cell counts}

Using a light microscope with a calibrated graticule eyepiece, the total number of eosinophils were counted in contiguous high power fields from the basement membrane to the outer border of the airway smooth muscle (i.e. inner wall area) around the entire circumference of the airway. Cells were not counted if they were in mucous glands or blood vessels and numbers were expressed as cells per millimetre of the measured $\mathrm{Pbm}$. Eosinophils were identified using morphological criteria: cells with prominent granular eosinophilic cytoplasm and with two nuclear lobules. Cells with more than two nuclear lobules were categorized as neutrophils. These were observed only occasionally in the airway wall.

All lymphocytes were counted in membranous airways, and the cell numbers were expressed per millimetre of $\mathrm{Pbm}$. In large and small cartilaginous airways, the numbers of lymphocytes between the basement membrane and the outer border of the airway smooth muscle were counted in at least eight randomly chosen high power fields (hpf) using a calibrated graticule eyepiece. The area of tissue in which lymphocytes were counted was measured for each hpf and the mean number of cells per millimetre squared was calculated. Preliminary work had shown that the cumulative mean cell count varied by less than $5 \%$ after measurement of eight random fields. The mean lymphocyte number per millimetre squared was then multiplied by the total inner wall area to calculate the total number of lymphocytes, and this number was then divided by the $\mathrm{Pbm}$ to yield cells per millimetre Pbm. Cells were identified as lymphocytes using morphological criteria: dark, even-staining small nuclei with scanty cytoplasm. Identification of 
a)

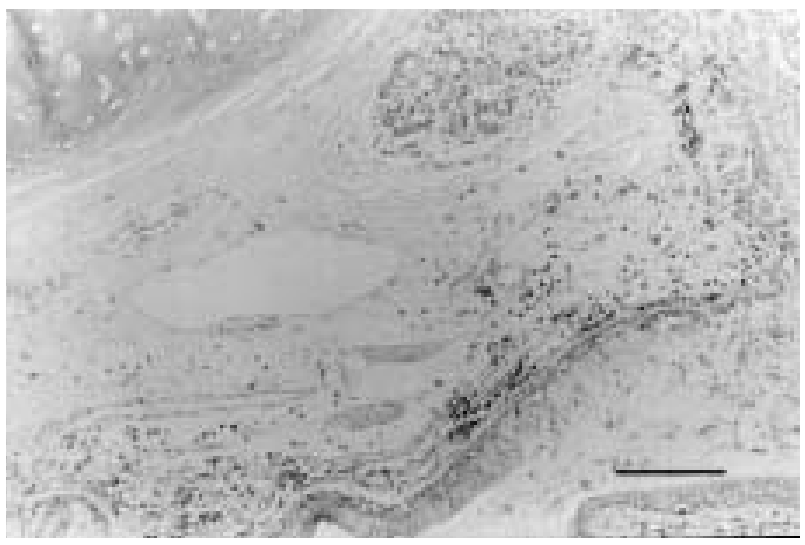

b)

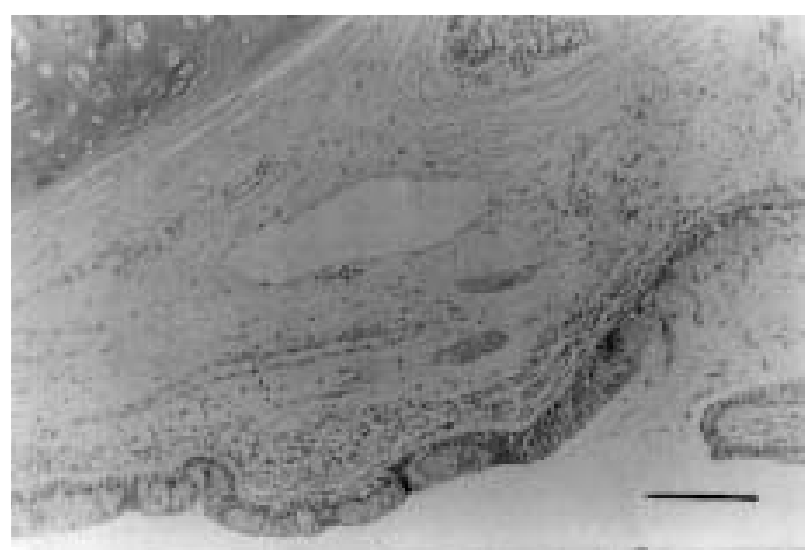

Fig. 1. - a) A high power field of the submucosa from a transverse cartilaginous airway stained with the T-cell marker, UCHL 1, from a case of fatal asthma; and b) a contiguous serial section from the same airway stained with the B-cell marker, L26. Note the intensive positive staining for T-cells and the relative absence of B-cells. (Scale bar $=50 \mu \mathrm{m})$

lymphocytes was confirmed with preliminary studies using the leucocyte common antigen (LCA) monoclonal antibody as a pan leucocyte marker, the UCHL1 antibody as a "primed" T-cell marker (fig. 1a), and L26 as a specific B-cell marker. Very few B-cells were seen (fig. 1b).

Additional confirmation using morphological criteria was obtained by interobserver comparisons with pathologists and cytologists experienced in observation of pulmonary tissue. The inclusion of immature monocytes in the counts cannot be excluded, although it was clear that using specific markers, T-cells accounted for the vast majority of cells meeting our morphological criteria. Aggregates of lymphocytes identified on low power were not included in the counting.

\section{Data analysis}

The distribution of cell counts was normalized by logarithmic transformation. For each case, the mean eosinophil and lymphocyte counts per millimetre $\mathrm{Pbm}$ were calculated for arbitrary airway size groups: corresponding to membranous airways $(\mathrm{Pbm}<6 \mathrm{~mm})$; small cartilaginous airways (Pbm 6-16 mm); and large cartilaginous airways $(\mathrm{Pbm}>16 \mathrm{~mm})$. These airway size groups correspond to airway diameters of $<2,2-5$ and $>5 \mathrm{~mm}$, respectively. The mean cell counts from each case within each size group were combined, and the grand mean $( \pm \mathrm{SD})$ for that size group was calculated for case groups.

Comparisons between case groups (control, nonfatal, fatal) were made using a one-way analysis of variance (ANOVA). When a significant $\mathrm{p}$-value was found $(\mathrm{p}<$ 0.05) a Tukey-Kramer multiple comparison post hoc test was performed to determine which groups were different. Differences between groups with and without hay fever/allergies and according to treatment were tested using a Student's unpaired t-test or a Mann-Whitney U-test, depending on the normality of the distributions of cell counts. To investigate the degree to which a single airway specimen represents the overall distribution of inflammatory cells throughout the bronchial tree, the analysis was repeated by selecting at random, from each case, one airway with a $\mathrm{Pbm}$ close to the overall mean for each size group.

\section{Results}

\section{Subjects}

There were 10 cases in each group, with similar age and sex distributions in the fatal and nonfatal asthma groups. There were more males in the control group (table 1). All cases of fatal asthma were using inhaled corticosteroids and bronchodilators, and $70 \%$ were using oral corticosteroids. Seventy percent of the fatal asthma cases had missed work and had previously been admitted to a hospital because of asthma. Eight of the nine subjects with a recent value of FEV1 had airflow obstruction: FEV $1<65 \%$ of the predicted value. The cases of nonfatal asthma in general had mild asthma. They all used inhaled bronchodilators but only two were using inhaled corticosteroids, and only half had ever taken time off work because of asthma. Results of lung function tests were not available for any of this group. Causes of death were: cardiac disease $(n=3)$; carbon monoxide poisoning $(\mathrm{n}=2)$; hanging $(\mathrm{n}=2)$; motor vehicle accidents $(n=2)$; and gunshot wound $(n=1)$. For control cases, the causes of death were: carbon monoxide poisoning $(\mathrm{n}=3)$; hanging $(\mathrm{n}=2)$; motor vehicle accident $(n=1)$; asphyxiation $(n=1)$; coronary heart disease $(n=1)$; intracranial haemorrhage $(n=1)$; and liver disease $(n=1)$.

\section{Airway sampling}

Each subject had cells counted in at least three large cartilaginous airways, three small cartilaginous airways, and at least four membranous airways. The numbers of airways examined and the distribution of airway sizes $(\mathrm{Pbm})$ were similar in each case group (table 2$)$.

\section{Lymphocytes}

The lymphocyte counts per millimetre $\mathrm{Pbm}$ for each case group in the three airway size groups are shown 
Table 1. - Subject characteristics

\begin{tabular}{|c|c|c|c|}
\hline & $\begin{array}{l}\text { Fatal } \\
(\mathrm{n}=10)\end{array}$ & $\begin{array}{c}\text { Nonfatal } \\
(\mathrm{n}=10)\end{array}$ & $\begin{array}{c}\text { Control } \\
(\mathrm{n}=10)\end{array}$ \\
\hline Age $^{\#}$ yrs & $\begin{array}{c}41 \\
(18-64)\end{array}$ & $\begin{array}{c}32 \\
(18-58)\end{array}$ & $\begin{array}{c}38 \\
(17-65)\end{array}$ \\
\hline $\operatorname{Sex} \quad M / F$ & $5 / 5$ & $6 / 4$ & $8 / 2$ \\
\hline Duration of asthma yrs & $\begin{array}{c}28 \\
(2-65)\end{array}$ & $\begin{array}{c}15 \\
(2-28)\end{array}$ & $\begin{array}{l}0 \\
0\end{array}$ \\
\hline \multicolumn{4}{|l|}{ Treatment \% } \\
\hline Oral corticosteroids & 70 & 0 & 0 \\
\hline Inhaled corticosteroids & 100 & 20 & 0 \\
\hline Theophylline & 90 & 20 & 0 \\
\hline Beta-agonist & 100 & 100 & 0 \\
\hline $\begin{array}{l}\text { Hospitalization due to asthma } \% \\
\text { Frequency of symptoms } \%\end{array}$ & 70 & 12 & 0 \\
\hline Daily & 90 & $33(n=9)$ & 0 \\
\hline Occasional $\left(<1\right.$ event $\cdot$ week $\left.^{-1}\right)$ & 10 & 67 & 0 \\
\hline
\end{tabular}

\#: mean, and range in parenthesis. M: male; F: female.

Table 2. - Basement membrane perimeters $(\mathrm{mm})$ of airways sampled from three levels of the bronchial tree

\begin{tabular}{lccc}
\hline & \multicolumn{3}{c}{ Basement } \\
& Fatal & membrane perimeter mm \\
& Nonfatal & Control \\
\hline Large & $18.2(2.2)$ & $18.1(1.7)$ & $18.1(1.5)$ \\
cartilaginous & $\mathrm{n}=26$ & $\mathrm{n}=30$ & $\mathrm{n}=24$ \\
Small & $11.6(0.8)$ & $11.4(0.8)$ & $11.1(0.8)$ \\
cartilaginous & $\mathrm{n}=48$ & $\mathrm{n}=56$ & $\mathrm{n}=43$ \\
Membranous & $2.7(0.8)$ & $2.5(0.7)$ & $2.8(0.8)$ \\
airways & $\mathrm{n}=58$ & $\mathrm{n}=60$ & $\mathrm{n}=53$ \\
& & &
\end{tabular}

Values are presented as mean, and SD in parenthesis.

in figure 2. In large cartilaginous airways ( $\mathrm{Pbm}>16 \mathrm{~mm})$ the number of lymphocytes in control cases (mean $\pm \mathrm{SD})$ was $108 \pm 61$ cells $\cdot \mathrm{mm}^{-1} \mathrm{Pbm}$, which was significantly lower than in cases of fatal asthma $\left(259 \pm 167\right.$ cells $\cdot \mathrm{mm}^{-1}$ $\mathrm{Pbm} ; \mathrm{p}<0.05)$, but not significantly different from cases of nonfatal asthma $\left(224 \pm 113\right.$ cells $\left.\cdot \mathrm{mm}^{-1} \mathrm{Pbm} ; \mathrm{p}=0.056\right)$.

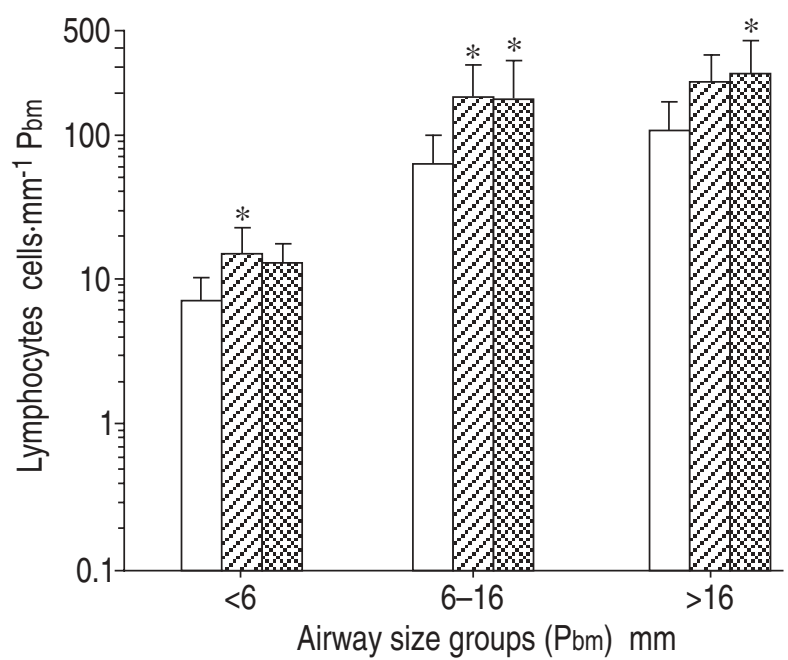

Fig. 2. - Lymphocyte numbers $\mathrm{mm}^{-1} \mathrm{Pbm}$ in cases of fatal asthma (\$) , nonfatal asthma ( $\square$ ), and control cases $(\square)$ in membranous airways $(<6 \mathrm{~mm})$, small cartilaginous airways $(6-16 \mathrm{~mm})$, and large cartilaginous airways $(>16 \mathrm{~mm})$. Values are presented as mean \pm sD. $\mathrm{Pbm}$ : basement membrane perimeter. $*$ : $\mathrm{p}<0.05$, compared to control cases.
In small cartilaginous airways $(\mathrm{Pbm}=6-16 \mathrm{~mm})$, the number of lymphocytes in control cases $\left(62 \pm 38\right.$ cells $\cdot \mathrm{mm}^{-1}$ $\mathrm{Pbm})$ was significantly lower than in cases of fatal asthma $\left(178 \pm 140\right.$ cells $\left.\cdot \mathrm{mm}^{-1} \mathrm{Pbm} ; \mathrm{p}<0.05\right)$ and nonfatal asthma $\left(182 \pm 112\right.$ cells $\left.\cdot \mathrm{mm}^{-1} \mathrm{Pbm} ; \mathrm{p}<0.05\right)$. In membranous airways $(\mathrm{Pbm}<6 \mathrm{~mm})$, the number of lymphocytes in control cases was $7 \pm 3$ cells $\cdot \mathrm{mm}^{-1} \mathrm{Pbm}$, which was significantly lower than cases of nonfatal asthma $(15 \pm 8$ cells $\left.\cdot \mathrm{mm}^{-1} \mathrm{Pbm} ; \mathrm{p}<0.05\right)$ but not significantly different from cases of fatal asthma $\left(13 \pm 5\right.$ cells $\cdot \mathrm{mm}^{-1} \mathrm{Pbm} ; \mathrm{p}=$ $0.058)$. It can be seen that lymphocyte numbers per millimetre $\mathrm{Pbm}$ increased with increasing airway size. The same trend was seen if lymphocyte numbers were corrected for airway wall area, i.e. lymphocyte density increased with airway size.

Using only one airway per size group from each case, the lymphocyte counts showed a similar relationship between case groups (fig. 3) as that seen when all airways were included. In large cartilaginous airways, the number of lymphocytes was $110 \pm 40$ cells $\cdot \mathrm{mm}^{-1} \mathrm{Pbm}$ in

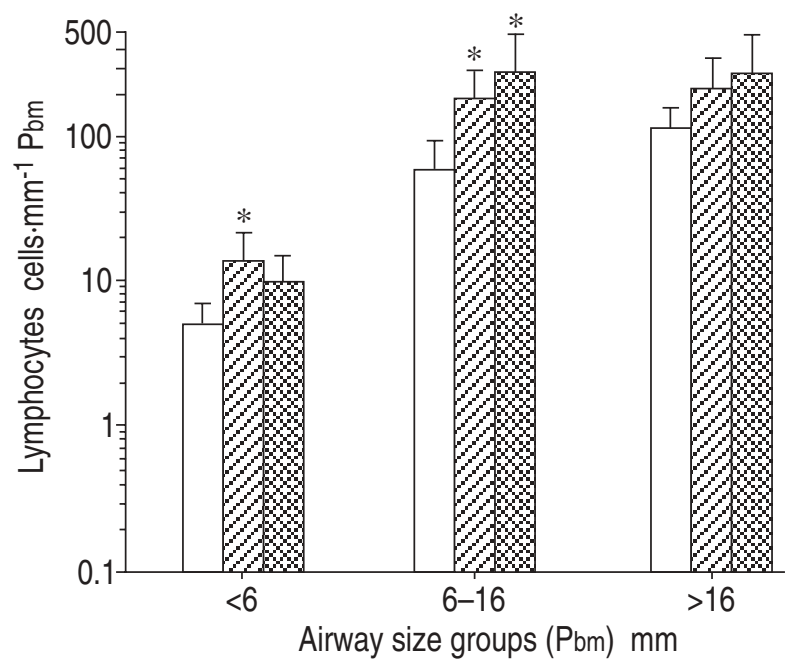

Fig. 3. - Lymphocyte numbers $\cdot \mathrm{mm}^{-1} \mathrm{Pbm}$ from a single airway in cases of fatal asthma ( $\beta$ ), nonfatal asthma ( $\square$ ), and control cases $(\square)$ in membranous airways $(<6 \mathrm{~mm})$, small cartilaginous airways $(6-16 \mathrm{~mm})$, and large cartilaginous airways $(>16 \mathrm{~mm})$. Values are presented as mean \pm SD. Pbm: basement membrane perimeter. * $: \mathrm{p}<0.05$, compared to control cases. 
control cases, $256 \pm 210$ cells $\cdot \mathrm{mm}^{-1} \mathrm{Pbm}$ in cases of fatal asthma ( $\mathrm{p}=0.059$, compared to controls) and $206 \pm$ 112 cells $\cdot \mathrm{mm}^{-1} \mathrm{Pbm}$ in nonfatal asthma cases $(\mathrm{p}=0.061$, compared to controls). In small cartilaginous airways, the number of lymphocytes was $58 \pm 62$ cells $\cdot \mathrm{mm}^{-1} \mathrm{Pbm}$ in control cases, $272 \pm 212$ cells $\cdot \mathrm{mm}^{-1} \mathrm{Pbm}$ in cases of fatal asthma ( $\mathrm{p}<0.05$, compared to controls) and $182 \pm 91$ cells $\cdot \mathrm{mm}^{-1} \mathrm{Pbm}$ in nonfatal asthma cases ( $\mathrm{p}<0.05$, compared to control). In membranous airways, the number of

a) 1000
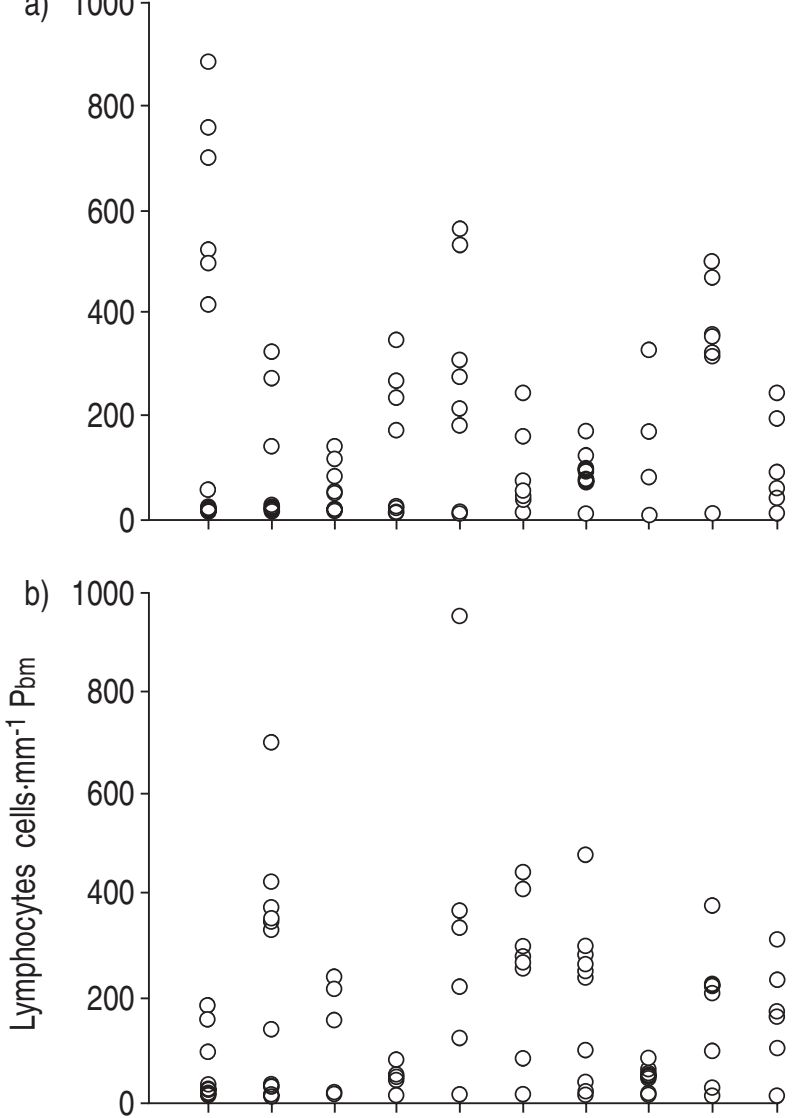

c) 1000

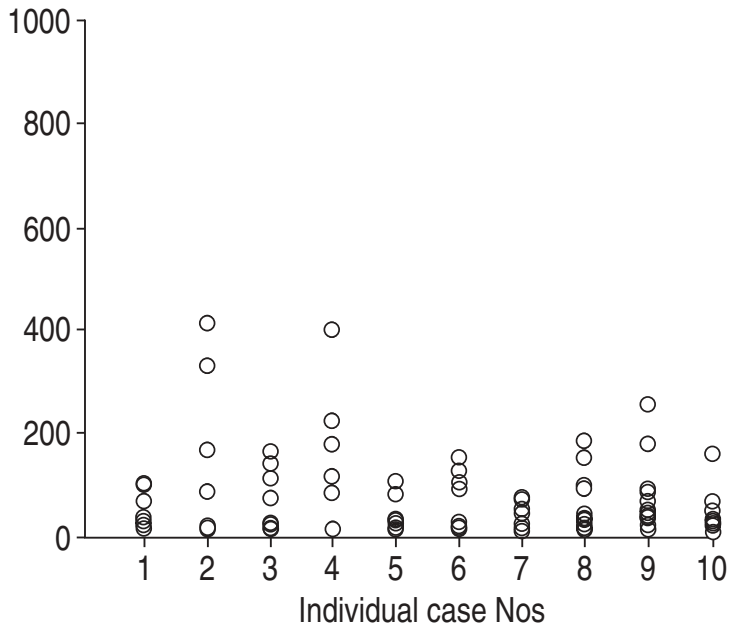

Fig. 4. - Lymphocyte numbers $\cdot \mathrm{mm}^{-1} \mathrm{Pbm}$ in large cartilaginous, small cartilaginous and membranous airways in: a) fatal; b) nonfatal; and c) control cases. Open circles represent the cell count from one airway. Numbers 1-10 represent individual cases. Pbm: basement membrane perimeter. lymphocytes was $5 \pm 2$ cells $\cdot \mathrm{mm}^{-1} \mathrm{Pbm}$ in control cases, $14 \pm 8$ cells $\cdot \mathrm{mm}^{-1} \mathrm{Pbm}$ in cases of nonfatal asthma $(\mathrm{p}<$ 0.05 , compared to control cases), and $10 \pm 5$ cells $\cdot \mathrm{mm}^{-1}$ $\mathrm{Pbm}$ in cases of fatal asthma ( $\mathrm{p}=0.058$, compared to control cases).

Figure 4 shows the distribution of lymphocyte counts between cases in each group. There was a seven fold variation in the range of mean lymphocyte counts between cases of fatal asthma, eight fold variation in nonfatal cases, and a three fold variation in control cases. Although there was a great deal of overlap, $60 \%$ of nonfatal and fatal cases had more than one airway with more than 300 lymphocytes per millimetre $\mathrm{Pbm}$, whilst only $10 \%$ of control cases had more than one airway with more than 300 lymphocytes per millimetre $\mathrm{Pbm}$.

\section{Eosinophils}

Eosinophils per millimetre $\mathrm{Pbm}$ for each case group in the three airway size groups are shown in figure 5. In large cartilaginous airways, the number of eosinophils in control cases was $1.5 \pm 0.5$ cells $\cdot \mathrm{mm}^{-1} \mathrm{Pbm}$, in cases of nonfatal asthma $1.8 \pm 0.4$ cells $\cdot \mathrm{mm}^{-1} \mathrm{Pbm}$, and in cases of fatal asthma $11 \pm 11$ cells $\cdot \mathrm{mm}^{-1} \mathrm{Pbm}(\mathrm{p}<0.05$, compared to control and nonfatal asthma cases). In small cartilaginous airways, the number of eosinophils in control cases was $1.8 \pm 0.5$ cells $\cdot \mathrm{mm}^{-1} \mathrm{Pbm}$, in cases of nonfatal asthma $2.1 \pm 0.7$ cells $\cdot \mathrm{mm}^{-1} \mathrm{Pbm}$, and in cases of fatal asthma $11 \pm 12$ cells $\cdot \mathrm{mm}^{-1} \mathrm{Pbm}(\mathrm{p}<0.05$, compared to control and nonfatal asthma cases). In membranous airways, the number of eosinophils in control cases was $1.8 \pm 0.7$ cells $\cdot \mathrm{mm}^{-1} \mathrm{Pbm}$, in cases of nonfatal asthma $1.5 \pm 0.4$ cells $\cdot \mathrm{mm}^{-1} \mathrm{Pbm}$, and in cases of fatal asthma $3.0 \pm 1.5$ cells $\cdot \mathrm{mm}^{-1} \mathrm{Pbm}(\mathrm{p}<0.05$, compared to control and nonfatal asthma cases).

Using only one airway per size group from each case, the eosinophil counts showed a similar relationship between case groups (fig. 6) as that seen when all airways were included. In large cartilaginous airways, the number of eosinophils in control cases was

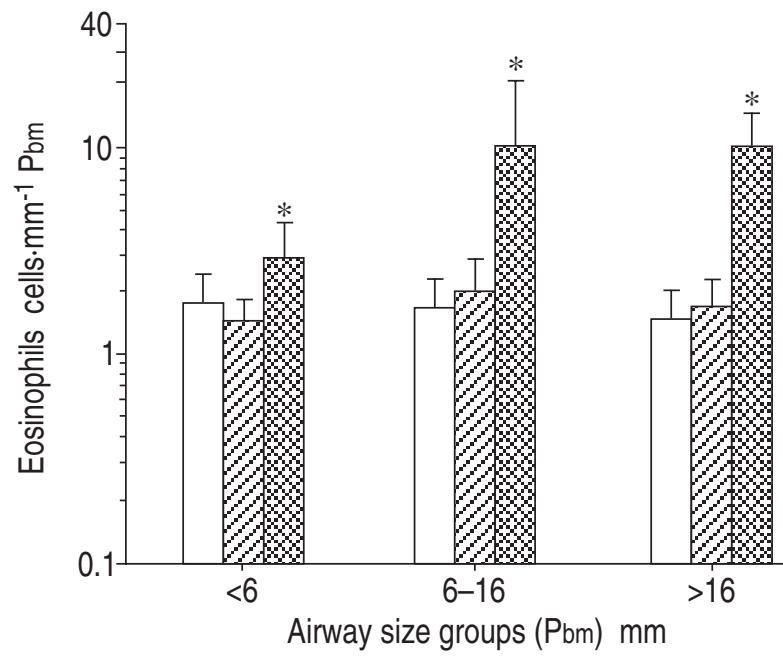

Fig. 5. - Eosinophil numbers $\cdot \mathrm{mm}^{-1} \mathrm{Pbm}$ in cases of fatal asthma ( $\$$ ), nonfatal asthma ( $\square$ ), and control cases $(\square)$ in membranous airways $(<6 \mathrm{~mm})$, small cartilaginous airways $(6-16 \mathrm{~mm})$, and large cartilaginous airways $(>16 \mathrm{~mm})$. Values are presented as mean \pm sD. $\mathrm{Pbm}$ : basement membrane perimeter. ${ }^{*}: \mathrm{p}<0.05$, compared to control cases. 


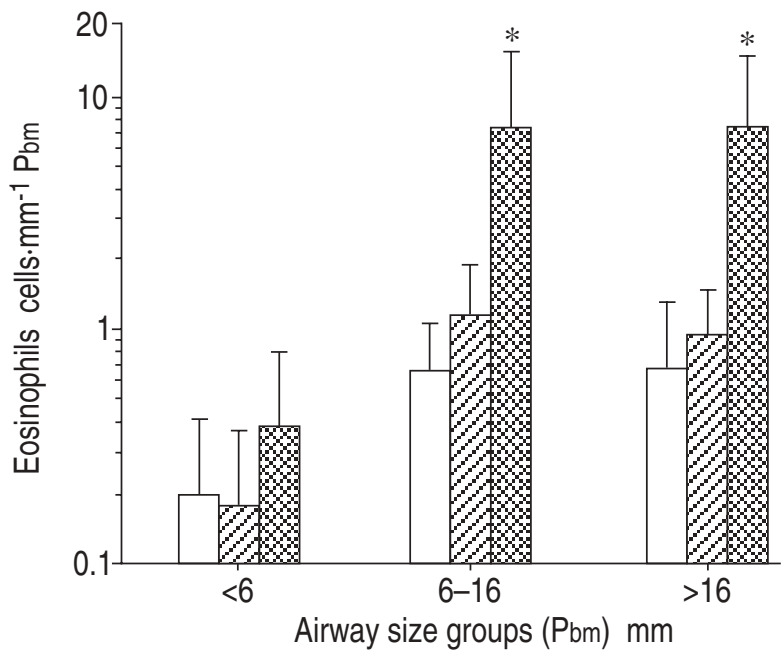

Fig. 6. - Eosinophil numbers $\cdot \mathrm{mm}^{-1} \mathrm{Pbm}$ from a single airway in cases of fatal asthma ( $\$$ ), nonfatal asthma $(\square)$, and control cases $(\square)$ in membranous airways $(<6 \mathrm{~mm})$, small cartilaginous airways $(6-16 \mathrm{~mm})$, and large cartilaginous airways $(>16 \mathrm{~mm})$. Values are presented as mean \pm SD. Pbm: basement membrane perimeter. $*: \mathrm{p}<0.05$, compared to control cases.

$0.7 \pm 0.6$ cells $\cdot \mathrm{mm}^{-1} \mathrm{Pbm}$, in cases of fatal asthma $7.6 \pm 7.3$ cells $\cdot \mathrm{mm}^{-1} \mathrm{Pbm}(\mathrm{p}<0.05$, compared to controls), and in nonfatal asthma cases $1.0 \pm 0.5$ cells $\cdot \mathrm{mm}^{-1} \mathrm{Pbm}$. In small cartilaginous airways, the number of eosinophils in control cases was $0.7 \pm 0.4$ cells $\cdot \mathrm{mm}^{-1} \mathrm{Pbm}$, in cases of fatal asthma $7.6 \pm 8.0$ cells $\cdot \mathrm{mm}^{-1} \mathrm{Pbm}(\mathrm{p}<0.05$ compared to controls) and in nonfatal asthma cases $1.1 \pm 0.8$ cells $\cdot \mathrm{mm}^{-1}$ $\mathrm{Pbm}$. In membranous airways, the number of eosinophils in control cases was $0.2 \pm 0.2$ cells $\cdot \mathrm{mm}^{-1} \mathrm{Pbm}$, in cases of nonfatal asthma $0.2 \pm 0.2$ cells $\cdot \mathrm{mm}^{-1} \mathrm{Pbm}$, and in cases of fatal asthma $0.4 \pm 0.4$ cells $\cdot \mathrm{mm}^{-1} \mathrm{Pbm}$. Eosinophil counts and density (cells per area) were greater in cartilaginous airways compared to membranous airways in fatal cases, but were not related to airway size in control and nonfatal cases, when all airways were included in the analysis.

Figure 7 shows the variability of eosinophil counts between cases in each group. There was a 23 fold variation in the range of mean eosinophil counts in cases of fatal asthma, nine fold variation in nonfatal cases, and an 11 fold variation in control cases. Only $20 \%$ of nonfatal cases had any airways ( 1 each) with $>5$ eosinophils $\cdot \mathrm{mm}^{-1}$ $\mathrm{Pbm}$, compared to $100 \%$ of fatal cases. No control cases had any airways with $>5$ eosinophils $\cdot \mathrm{mm}^{-1} \mathrm{Pbm}$, the highest being 3.8 eosinophils $\cdot \mathrm{mm}^{-1} \mathrm{Pbm}$.

The number of lymphocytes correlated more closely with the number of eosinophils in the fatal asthma cases $(\mathrm{r}=0.60 ; \mathrm{p}<0.0001)$ than in the nonfatal asthma cases $(\mathrm{r}=0.34 ; \mathrm{p}=0.001)$ or control cases $(\mathrm{r}=0.32 ; \mathrm{p}=0.001)$ (fig. 8). There was no significant difference in eosinophil or lymphocyte numbers between cases with or without a history of allergy or hay fever, or in relation to treatment.

\section{Discussion}

In this study, increased numbers of lymphocytes were found in cases both of fatal and nonfatal asthma, and increased numbers of eosinophils in cases of fatal asthma, a)
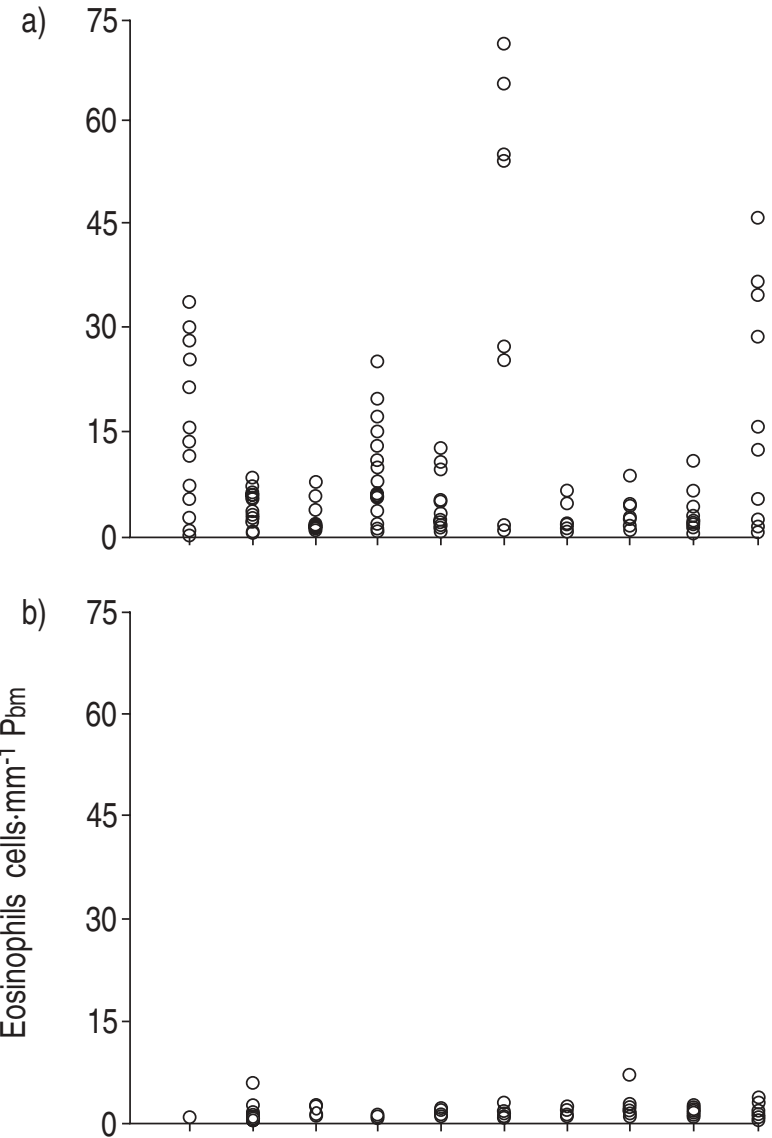

c)

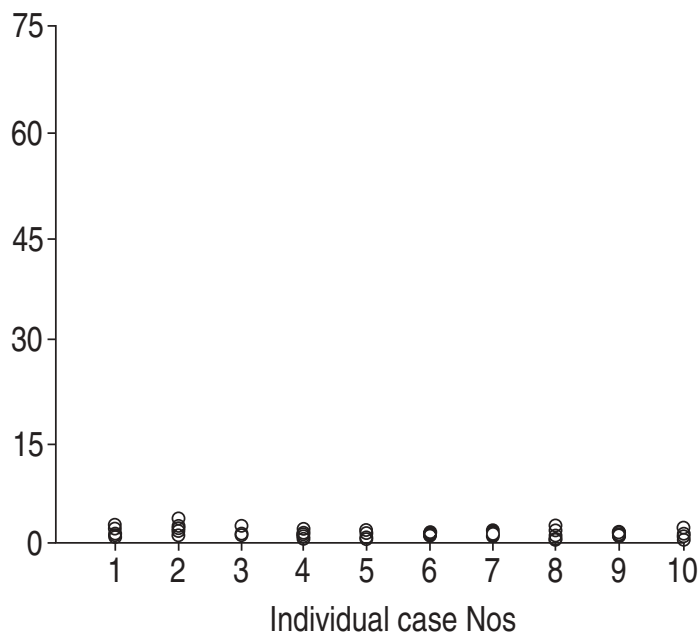

Fig. 7. - Eosinophil numbers $\cdot \mathrm{mm}^{-1} \mathrm{Pbm}$ in large cartilaginous, small cartilaginous and membranous airways in: a) fatal; b) nonfatal; and c) control cases. Open circles represent the cell count from one airway. Numbers 1-10 represent individual cases. Pbm: basement membrane perimeter.

compared to control cases. The variability of eosinophil numbers was greater than for lymphocytes both within and between cases. Numbers of eosinophils were related to the numbers of lymphocytes. Differences between case groups were similar in large and small airways, and when only single sections from each case in each airway size group were examined. These findings suggest that asthma is best characterized by increased numbers of lymphocytes which are evenly distributed throughout 


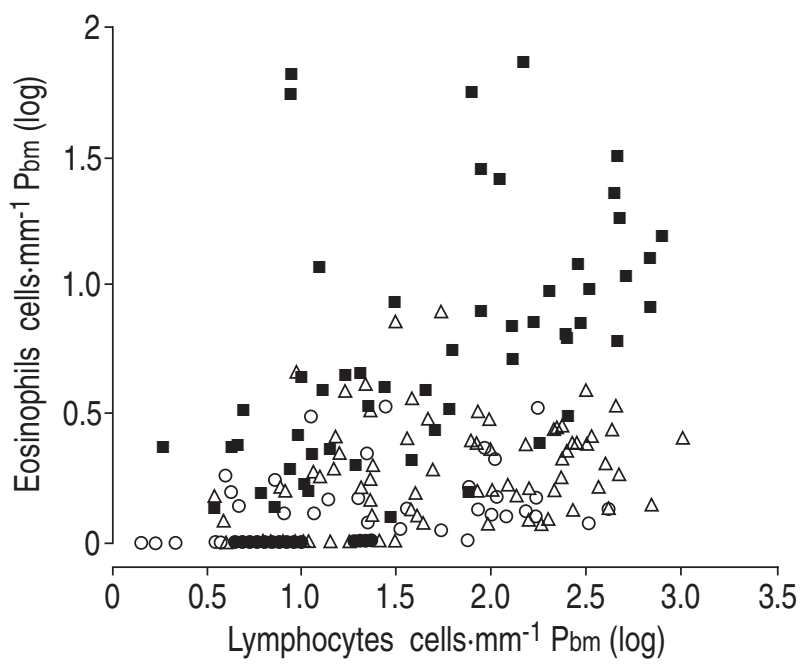

Fig. 8. - Lymphocyte numbers $\mathrm{mm}^{-1} \mathrm{Pbm}(\log )$ versus eosinophil numbers $\cdot \mathrm{mm}^{-1} \mathrm{Pbm}(\log )$ in all airways from cases of fatal asthma $(\boldsymbol{\square})$, nonfatal asthma cases $(\triangle)$, and control cases $(O)$. Pbm: basement membrane perimeter.

the bronchial tree, and that other factors may influence eosinophil numbers. The results indicate that bronchial biopsies of the proximal bronchial tree will reliably characterize the pattern of inflammation in the airways of different cases. Comparisons of airway samples need to allow for the possible effects of airway size on the absolute number of cells present.

In terms of treatment requirements, frequency of symptoms, and time away from work or school due to asthma, the nonfatal cases of asthma could be considered as mild and the fatal cases of asthma as severe. Therefore, the differences observed between these case groups may only be related to severity rather than to factors related to death from asthma. Studies of cases of severe nonfatal asthma are needed to resolve these issues. In this study, we found no correlation between inflammatory cell numbers and the presence of allergy/hay fever or between inflammatory cell numbers and the use of medications for asthma. This finding may be due to the small number of cases with complete histories regarding details of treatment, or because information regarding the presence or absence of atopy defined by positive skin-prick tests or measurements of serum immunoglobulin (IgE) were not always available.

Defined morphological criteria were used to identify eosinophils and lymphocytes in airway tissue stained with haematoxylin and eosin, and findings were compared to those of experienced cytologists. The intra- and interobserver error for cell counts on these tissues has been shown to be less than $10 \%$ [18]. This method for quantifying cell numbers may lead to an underestimation of cell numbers if their morphology is disrupted due to postmortem effects (e.g. autolysis), cell activation (e.g. degranulation), or if the cell structure is altered due to histological processing. Since these sources of variability are likely to be similar in all the cases that we observed, it is unlikely that the differences in cell counts between the groups in this study would be artefactual.

A number of previous studies have shown increased numbers of lymphocytes in the airways of cases of fatal asthma $[1-3,19,20]$, and in cases of mild asthma using BAL and bronchial biopsy [11-13, 15, 17]. The lymphocytes are essentially all T-cells, and show increased activation compared to controls $[11-13,15]$. In the present study, we have demonstrated that lymphocyte numbers are increased both in cartilaginous and membranous airways although cell counts increase with airway size. Interestingly, lymphocyte numbers were similar in the fatal and nonfatal asthma groups, despite their clear differences in severity. This is consistent with the hypothesis that in asthmatic inflammation, the lymphocyte is the principal regulating inflammatory cell, which may determine the more variable concentrations of effector cells, such as eosinophils.

The initiating stimulus for persistent airway inflammation in asthma is not known. Possibilities include the persistent interaction between a sensitized host and environmental stimuli interacting at the interface of the conducting airways. The bronchial tree is richly supplied with a systemic circulation and the epithelium contains a rich network of immune surveillance cells [21]. Alternatively, altered host antigen (e.g. airway epithelial cells) might be a source of chronic inflammatory stimulus. The present study suggests a reasonably uniform distribution of lymphocytic inflammatory cell infiltration in large and small airways. This suggests a widespread uniform deposition of an exogenous stimulus, amplification or accumulation of focal areas of inflammation, or a widespread altered host antigen. The variable numbers of eosinophils may, on the other hand, represent a more transient response to intermittent exogenous stimuli. Cookson et al. [22] have shown that falls in peripheral eosinophil counts parallel the late asthmatic response following allergen inhalation. WARDLAW et al. [5] found increased numbers of eosinophils in BAL from 11 atopic asthmatics but not in the accompanying bronchial biopsies from the same patients [17], and it was suggested that this may be because eosinophils detected in the airway lumen by BAL might gain access from a site distal to that which can be sampled by bronchoscopy. This would not explain the present results, however, since all our samples were in the bronchial wall, where the eosinophils present are presumably derived from the local bronchial circulation. It is unlikely that eosinophils migrate from the lumen into the bronchial wall.

In the present study, eosinophil counts were increased in all airway sizes in fatal cases of asthma, although their variability was greater than for lymphocytes. Numerous studies have described increased eosinophil numbers in cases of fatal asthma [1-3, 19, 20, 23-25]. In the nonfatal cases, we found that eosinophil densities were no different from control cases. This observation has been made previously $[8,17]$, but is at odds with numerous biopsy and BAL studies [4-7, 9-15, 17, 26]. These differences may be due to a number of factors, including differences in the severity and treatment of asthma in the sample population, differences in staining procedures, and differences in atopic status in the cases examined. Patients with asthma who become symptomatic following steroid withdrawal have increased numbers of eosinophils [27]; LAURSEN et al. [28] were unable to find any eosinophils in bronchial biopsies obtained from 10 steroid-dependent asthmatics undergoing 
long-term treatment with high daily doses of inhaled budesonide. In the present study, cases of nonfatal asthma were included if there was a history of asthma ever in their medical records, and there was no information as to whether they were symptomatic or not at the time of death. As in the present study, previous studies [8, 17] that did not show a difference between eosinophil numbers in mild asthmatics and nonasthmatics did not use the EG2 monoclonal antibody, a marker of eosinophil activation, to enumerate eosinophils. Once activated, eosinophils may degranulate and lose their usual morphological structure, thus making them difficult to identify in tissue stained with haematoxylin and eosin. Eosinophil activation has been demonstrated in milder cases of asthma [12, 15, 29] using the EG2 monoclonal antibody, which recognizes the cleaved form of eosinophilic cationic protein. Therefore, eosinophil numbers may have been underestimated in the present study. Bronchial biopsy studies [29-31] have shown increased numbers of submucosal eosinophils in atopic non-asthmatics compared to nonatopic nonasthmatics, and LAITINEN et al. [14] found that the presence or absence of atopy correlated with the number of eosinophils in the epithelium, but not in the lamina propria, of subjects with mild asthma. In the present study, since it was not possible to fully characterize atopic status in all of the cases of asthma or in any of the control cases, atopy cannot be excluded as a confounder of these results.

In the present study, we have shown that, although more variable than lymphocytes, eosinophil numbers were related to severity of, or death from asthma, and differences between groups were similar in large and small airways. In cases of fatal asthma, the numbers of eosinophils were more closely related to the number of lymphocytes than in the nonfatal asthma and control cases. Numerous studies $[3,12,15,16,19,20,24,32-$ 34] have shown increased numbers both of lymphocytes and eosinophils in asthmatic airways, although not over the range of asthma severity and airway sizes sampled in this study. It has been suggested that cell/ endothelial adhesion mechanisms and chemoattractant cytokines [35-38] may provide a common pathway of extravasation for lymphocytes and eosinophils at sites of inflammation. It is possible that the increased numbers of eosinophils in the cases of fatal asthma is due to factors related not only to severity but also to a final episode of asthma. Sur et al. [20] have shown that cell profiles in the airway wall may be temporally related to a fatal attack of asthma, and we have recently confirmed these findings [39]. In both studies, neutrophils were observed in much smaller numbers than lymphocytes and eosinophils in cases of fatal asthma, and may be important in the pathogenesis of a fatal attack of asthma.

We found that the density of lymphocytes and, to a lesser extent, eosinophils increased with airway size, and that the pattern of distribution of cell density was similar between case groups even when single airway sections were chosen at random for comparison. This suggests that if a bronchial wall biopsy is representative of the inflammatory infiltrate within an airway, then biopsy of proximal airways will be representative of the inflammatory process throughout the bronchial tree in cases of asthma. The present study also confirms that the site of airway inflammation both in mild and severe asthma is in the large and small conducting airways. We have previously shown that altered airway structure, including thickening of the airway wall, is present both in the large and small airways in severe (fatal) cases of asthma, but only in the small airways of mild cases [40]. The relationship between airway inflammation and structural change is of interest in asthma. Longstanding asthma is related to fixed airway narrowing [41], and the rapidity of death from an attack of asthma is related not only to inflammatory cell profiles but also to the size of mucous glands [39]. It is assumed that chronic airway inflammation results in structural change. The results of the present study suggest that airway inflammation, characterized by lymphocytic infiltration, is quite uniform in asthma compared to the variation seen in structure [40]. The factors which determine increased airway eosinophils and marked structural change, and therefore "severity" in asthma, need to be determined.

\section{References}

1. Dunnill MS. The pathology of asthma with special reference to changes in the bronchial mucosa. J Clin Pathol 1960; 13: 27-33.

2. Houston JC, De Navasquez S, Trounce JR. A clinical and pathological study of fatal cases of status asthmaticus. Histopathology 1953; 2: 407-421.

3. Saetta M, Di Stefano AD, Rosina C, Thiene G, Fabbri LM. Quantitative structural analysis of peripheral airways and arteries in sudden fatal asthma. Am Rev Respir Dis 1991; 143: 138-143.

4. Beasley R, Roche W, Roberts JA, Holgate ST. Cellular events in the bronchi in mild asthma and after bronchial provocation. Am Rev Respir Dis 1989; 139: 806-817.

5. Wardlaw AJ, Dunnett S, Gleich GJ, Collins JV, Kay AB. Eosinophils and mast cells in bronchoalveolar lavage in mild asthma: relationship to bronchial hyperreactivity. Am Rev Respir Dis 1988; 137: 62-69.

6. Bousquet J, Chanez P, Lacoste JY, et al. Eosinophilic inflammation in asthma. $N$ Engl J Med 1990; 323: 1033-1039.

7. Foresi A, Bertorelli G, Pesci A, Chetta A, Olivieri D. Inflammatory markers in bronchoalveolar lavage and in bronchial biopsy in asthma during remission. Chest 1990; 98: 528-535.

8. Lozewicz S, Gomez E, Ferguson H, Davies RJ. Inflammatory cells in the airways in asthma. $\operatorname{Br}$ Med $J 1988$; 297: 1515-1516.

9. Lundgren R, Soderberg M, Horstedt P, Stenling R. Morphological studies of bronchial mucosal biopsies from asthmatics before and after ten years of treatment with inhaled steriods. Eur J Respir Dis 1988; 1: 883-889.

10. Djukanovic R, Wilson JW, Britten KM, et al. Quantitation of mast cells and eosinophils in the bronchial mucosa of symptomatic atopic asthmatics and healthy control subjects using immunohistochemistry. Am Rev Respir Dis 1990; 142: 863-871.

11. Poulter LW, Power C, Burke C. The relationship between bronchial immunopathology and hyperresponsiveness in asthma. Eur Respir J 1990; 3: 792-799.

12. Bradley BL, Azzawi M, Jacobson M, et al. Eosinophils, T-lymphocytes, mast cells, neutrophils, and macrophages in bronchial biopsy specimens from atopic subjects 
with asthma: comparison with biopsy specimens from atopic subjects without asthma and normal control subjects and relationship to bronchial hyperresponsiveness. J Allergy Clin Immunol 1991; 88: 661-674.

13. Poston RN, Chanez P, Lacoste JY, Litchfield T, Lee $\mathrm{TH}$, Bousquet J. Immunohistochemical characterization of the cellular infiltration in asthmatic bronchi. Am Rev Respir Dis 1992; 145: 918-921.

14. Laitinen LA, Laitinen A, Haahtela T. A comparative study of the effects of an inhaled corticosteroid, budesonide, and a beta ${ }_{2}$-agonist, terbutaline, on airway inflammation in newly diagnosed asthma: a randomized, double-blind, parallel-group controlled trial. J Allergy Clin Immunol 1992; 90: 32-42.

15. Bentley AM, Menz G, Storz DS, et al. Identification of T-lymphocytes, macrophages, and activated eosinophils in the bronchial mucosa in intrinsic asthma. Am Rev Respir Dis 1992; 146: 500-506.

16. Bentley AM, Menz G, Robinson DS, Hamid Q, Kay AB, Durham SR. Increases in activated T-lymphocytes, eosinophils, and cytokine mRNA expression for interleukin-5 and granulocyte/macrophage colony-stimulating factor in bronchial biopsies after allergen inhalation challenge in atopic asthmatics. Am J Respir Cell Mol Biol 1993; 8: 35-42.

17. Jeffery PK, Wardlaw AJ, Nelson FC, Collins JV, Kay AB. Bronchial biopsies in asthma: an ultrastructural, quantitative study and correlation with hyperreactivity. Am Rev Respir Dis 1989; 140: 1745-1753.

18. Carroll NG, Lehman E, Barret J, Morton AR, Cooke C, James AL. Variability of airway structure and inflammation in normal subjects and in cases of nonfatal and fatal asthma. Path Res Pract 1996; 192(3): 238-248.

19. Azzawi M, Johnston PW, Majumdar S, Kay AB, Jeffrey PK. T-lymphocytes and activated eosinophils in airway mucosa in fatal asthma and cystic fibrosis. Am Rev Respir Dis 1992; 145: 1477-1482.

20. Sur S, Crotty TB, Kephart GM, et al. Sudden-onset fatal asthma: a distinct entity with few eosinophils and relatively more neutrophils in the airway submucosa? Am Rev Respir Dis 1993; 148: 713-719.

21. Holt PG, Schon-Hegrad MA, Oliver J, Holt BJ, McMenamin PG. A contiguous network of dendritic antigen presenting cells within the respiratory epithelium. Int Arch Allergy Appl Immunol 1990; 91: 155-159.

22. Cookson WO, Craddock CF, Benson MK, Durham SR. Falls in peripheral eosinophil counts parallel the late asthmatic response. Am Rev Respir Dis 1989; 139(2): 458-462.

23. Cutz E, Levison H, Cooper DM. Ultrastructure of airways in children with asthma. Thorax 1978; 8: 207-213.

24. Jeffery PK. Morphology of the airway wall in asthma and in chronic obstructive pulmonary disease. Am Rev Respir Dis 1991; 143: 1152-1160.

25. Fabbri LM, Danieli D, Crescioli S, Bevilacqua P, Meli S, Saetta M, Mapp CE. Fatal asthma in a subject sensitized to toluene diisocyanate. Am Rev Respir Dis 1988; 137: 1494-1498.

26. Robinson DS, Bentley AM, Hartnell A, Kay AB, Durham SR. Activated memory T-helper cells in bronchoalveolar lavage fluid from patients with atopic asthma: rela- tion to asthma symptoms, lung function, and bronchial responsiveness. Thorax 1993; 48: 26-32.

27. Gibson PG, Wong BJ, Hepperle MJ, et al. A research method to induce and examine a mild exacerbation of asthma by withdrawal of inhaled corticosteroid. Clin Exp Allergy 1992; 22(5): 525-532.

28. Laursen LC, Taudorf E, Borgeskov S, Kobayashi T, Jensen H, Weeke B. Fiberoptic bronchoscopy and bronchial mucosal biopsies in asthmatics undergoing long-term high-dose budesonide aerosol treatment. Allergy 1988; 43: 284-288.

29. Azzawi M, Bradley B, Jeffery PK, et al. Identification of activated T-lymphocytes and eosinophils in bronchial biopsies in stable atopic asthma. Am Rev Respir Dis 1990; 142: 1407-1413.

30. Djukanovic R, Lai CKW, Wilson JW, et al. Bronchial mucosal manifestations of atopy: a comparison of markers of inflammation between atopic asthmatics, atopic nonasthmatics and healthy controls. Eur Respir J 1992; 5: 538-544.

31. Howarth P, Djukanovic R, Wilson J, Wilson S, Roche $\mathrm{W}$, Holgate S. The influence of atopy on the endobronchial appearance in atopic asthma: a comparison between atopic asthma, atopic nonasthma and nonatopic nonasthma. Am Rev Respir Dis 1990; 141(4): A500.

32. Ohashi Y, Motojima S, Fukuda T, Makino S. Airway hyperresponsiveness, increased intracellular spaces of bronchial epithelium, and increased infiltration of eosinophils and lymphocytes in bronchial mucosa in asthma. Am Rev Respir Dis 1992; 145: 1469-1476.

33. Aikawa T, Shimura S, Sasaki H, Ebina M, Takishima T. Marked goblet cell hyperplasia with mucus accumulation in the airways of patients who died of severe acute asthma attack. Chest 1992; 101: 916-921.

34. Dunnill MS, Massarella GR, Anderson JA. A comparison of the quantitative anatomy of the bronchi in normal subjects, in status asthmaticus, in chronic bronchitis, and in emphysema. Thorax 1969; 24: 176-179.

35. Berman JS, Weller PF. Airway eosinophils and lymphocytes in asthma. Am Rev Respir Dis 1992; 145: $1246-1248$.

36. Haskard DO, Lee TH. The role of leukocyte-endothelial interactions in the accumulation of leukocytes in allergic inflammation. Am Rev Respir Dis 1992; 145: S10-S13.

37. Montefort S, Holgate ST, Howarth PH. Leucocyte-endothelial adhesion molecules and their role in bronchial asthma and allergic rhinitis. Eur Respir J 1993; 6: 10441054.

38. Furfaro S, Berman JS. The relation between cell migration and activation in inflammation: beyond adherence. Am J Respir Cell Mol Biol 1992; 7: 248-250.

39. Carroll NG, Carello S, Cooke C, James A. Airway structure and inflammatory cells in fatal attacks of asthma. Eur Respir J 1996; 9(4): 709-715.

40. Carroll NG, Elliot J, Morton AR, James AL. The structure of large and small airways in nonfatal and fatal asthma. Am Rev Respir Dis 1993; 147: 405-410.

41. Brown PJ, Greville HW, Finucane KE. Asthma and irreversible airflow obstruction. Thorax 1984; 39: 131136. 